\title{
Kaanbal: A Mobile Learning Platform Focused on Monitoring and Customization of Learning
}

\author{
https://doi.org/10.3991/ijet.v16i01.16483 \\ Cesar Huerta-Guerrero, Eduardo López-Domínguez $\left.{ }^{(}\right)$, Yesenia Hernández- \\ Velázquez, Saúl Domínguez-Isidro, Arturo Cueto-García \\ Laboratorio Nacional de Informática Avanzada, Xalapa, México \\ eduardo.lopez@lania.edu.mx \\ Jorge De-La-Calleja, María Auxilio Medina-Nieto \\ Universidad Politécnica de Puebla, Puebla, México
}

\begin{abstract}
Mobile learning is a learning modality characterized by ubiquitously allowing the learning monitoring and customization of students. In this context, several works have proposed software tools; however, these works lack learning monitoring and customization services based on the student's learning styles and context. This paper presents the analysis, design, development, and preliminary usability assessment of a mobile learning platform (Kaanbal), which considers learning styles and context information to provide the professor and student with services for learning monitoring and personalization. Kaanbal is composed of three main components: (1) A mobile learning object generator system, (2) A learning object repository, and (3) A student-oriented mobile application. The integration of these three components allows and facilitates the professor to implement strategies for learning monitoring and customization systematically. We carried out a usability assessment of the learning object generator system through a field study with five graduate-level professors. According to the obtained results, the learning object generator system presents a good acceptance, satisfaction, and applicability from the professors' perspective.
\end{abstract}

Keywords-Mobile learning objects, learning styles, learning customization, learning monitoring

\section{Introduction}

The technological progress related to telecommunications and mobile devices gave rise to a new teaching model known as m-learning [1]. M-learning or mobile learning is a learning modality supported by mobile technology to improve and reinforce learning processes [1], [2]. A property of M-learning is the capability for learning customization, which seeks the individualization of education based on the competences, aptitudes, and preferences of the students [3]. Therefore, the learning customization is based on the idea that students learn in different ways, at different speeds, and consid- 
ers the knowledge, needs, abilities, and perceptions of the student in the learning process.

In the new educational models, learning customization and monitoring are considered essential in the teaching-learning processes since both allow to have a studentcentered education, promoting the learning performance [4], [5]. Learning monitoring refers to any procedure that offers feedback and information about the progress of student learning, guiding the student to make their self-assessment or reflection of the learning process. Furthermore, the learning monitoring helps to identify students' competencies, what they know, and what they apply [6]. Therefore, the purpose of the learning monitoring is to guide students, offer guidance, correct errors, and help them overcome difficulties during the learning process, as well as control the process followed by the students [6].

Among the existing alternatives to implement the learning monitoring and customization is the use of mobile learning objects (MLOs) in the teaching-learning process. An MLO is any digital entity that can be used through mobile devices during the learning for the generation or reinforcement of knowledge [7]. MLOs can be a great help in learning strategies since they offer the opportunity to reuse activities, resources, and content [7]. In this regard, it is necessary to store and classify each MLO within a learning object repository (LOR), in order to be incorporated into the learning processes and guarantee its reuse. A LOR is a container of learning objects that provides facilities for cataloging, managing, consulting, viewing, and downloading learning objects [8].

Nevertheless, there are several challenges for professors to carry out the implementation of strategies that achieve the learning monitoring and customization, such as [3], [5], [9]-[12]: detection of the specific strengths and needs of each student in order to individualize their education; generation of quality MLOs that allow students to explore a specific area of knowledge independently; and the distribution of massively constructed MLOs among students through specialized LOR for this type of digital resources.

In this context, different works [13]-[27] have proposed software tools to carry out learning monitoring and customization based on the use of MLOs and LOR. We classify these works into three groups. The first group comprises works focused just on the learning customization [13]-[19], while in the second group we classify those works focused specifically on the learning monitoring [20]-[24], and the third group is composed of the works centered to the learning monitoring and customization [25][27]. Only the work proposed in [27] considers a repository where these learning objects are stored and retrieved automatically. On the other hand, a limited number of studies [25]-[27] have proposed solutions that provide the professor with monitoring services or learning customization. However, these studies did not consider the recommendation of those learning objects that were useful for other students with similar learning styles, and lack services that allow identifying the time that students invested in learning objects, and the times the student consulted a learning object.

In this paper, we present the analysis, design, development, and preliminary usability assessment of a mobile learning platform, which considers learning styles (active, reflective, theoretical and pragmatic) [28] and context information to provide the 
professor and student with various services for learning monitoring and personalization. Our platform, which we have called Kaanbal, consists of three main components:

1) A mobile learning object generator system (SiGOAM)

2) A mobile learning object repository (M-LOR)

3) A mobile application (AppMo) focused on the student

The main learning monitoring services provided to the professor by the platform proposed in this work are:

a) Building mobile learning objects based on the student's learning styles and context

b) Monitoring of the learning objects utilized by the students, as well as the total time invested and the times the student consulted a learning object

c) Suggest new learning objects by the professor to reinforce a particular subject difficult for the student

On the other hand, the main learning customization services offered by the platform are:

a) Identify student learning styles by applying the Honey - Alonso questionnaire (CHAEA) [28]

b) btain the context of the student based on the data collected by the sensors of the mobile device to determine the activity that the student is doing, which can be at rest or in motion

c) Recommendation of learning objects based on the learning styles and physical activity of the students

d) Recommendation of learning objects evaluated by other students with the same learning styles

To ensure the proper functioning of our platform, unit, and integration tests were performed, the results obtained in these tests indicate that the monitoring and customization services developed, achieve the requirements established in the analysis phase. In this work, we also carry out a usability evaluation of the mobile learning object generator system based on a field study with 5 graduate-level professors. According to the ISO/IEC 25010 usability standard [29], the satisfaction aspect of the users was assessed by applying the QUIS 7.0 questionnaire [30]. Based on the results obtained, the learning object generator system has full acceptance, satisfaction, and applicability from the professors' perspective. Therefore, our proposal is characterized by the related works proposed in the specialty literature by the following aspects:

a) Consider learning styles while incorporating mechanisms to obtain students' physical activity to provide recommendations of learning objects related to student preferences and conditions

b) Provide recommendations of learning objects that were useful to other students with equal or similar learning styles 
c) Allow monitoring of the studied learning objects by students

d) Integrate three tools in a single platform:

- a mobile learning object generator system

- a mobile learning object repository

- a mobile application

Which allows carrying a complete flow from when the professor designs and creates a mobile learning object, until the student consults it from a mobile device, and subsequently obtains feedback and self-assessment.

The paper is organized as follows: Section 2 presents state-of-the-art software tools that carry out learning monitoring and customization. Section 3 describes the platform overview, use case diagram, and relational data model of our proposal. Section 4 describes the services of our mobile learning platform. Section 5 contains the platform assessment and discussion. Section 6 presents the limitations of our work. Finally, conclusions and future work are presented in Section 7.

\section{State-of-the-Art}

Several works [13]-[27] have proposed software tools (applications, systems, or platforms) to carry out learning monitoring and customization. We classify these works into three groups. The first group comprises works focused just on learning customization. In contrast, in the second group, we classify those works focused specifically on learning monitoring. The third group is composed of the works oriented to the learning monitoring and customization.

\subsection{Works focused on learning customization}

In [13], an intelligent tutoring system was introduced, which detects the students' learning curve to provide recommendations on relevant and engaging topics. On the other hand, EduAdapt, introduced in [14] the adaptation of learning objects according to the device's features, learning styles, and context information of the student. Students must participate in a learning management system (LMS) and use a specific community related to a course. Another system proposed in [15] integrates an LMS to provide customized learning objects based on learning styles, prior knowledge, experience level, and student performance. Another work, COPAL, presented in [16] makes use of cognitive computing, data mining, and natural language processing to provide relevant information to the student. Moreover, it develops a customized learning route based on the student's learning styles. Another context-sensitive system proposed in [17] provides educational content referring to the English language according to the environmental characteristics of the student using GPS. A mobile application is presented in [18], which provides personalized mobile educational content, considering the student learning styles while incorporating context sensitivity to determine the appropriate learning format to be presented to the student. Another 
system proposed in [19] creates groups of students considering their preferences and interests to provide them with learning material that best suits the student's needs.

\subsection{Works focused on learning monitoring}

MobileEdu, introduced in [20], uses mobile devices to provide the following services: sending of notices, notification about tasks performed, discussion forums, as well as tests to assess the performance. A mobile learning platform presented in [21] is based on multi-agent systems and cloud computing, which is implemented as an LMS that allows to collect, store, and manage data and information about student activities. MLO is presented in [22] as a learning organizer with metacognitive support that offers students tools to plan, monitor, and evaluate their learning. Another system proposed in [23] provides information on the materials studied, the evaluations performed, and the evaluation results. Furthermore, it monitors the student's progress to interfere with the student's needs. Another system proposed in [24] offers personalized feedback in real-time in response to student characteristics to improve the student's learning ability.

\subsection{Works focused on monitoring and customization of learning}

MobiLearn, proposed in [25], is a context-aware learning system that offers the following monitoring services: notices of new activities, reminders, and evaluation results using SMS and social networks such as Facebook and Twitter. Concerning the customization side, the system suggests downloading mobile learning objects based on each student's learning style and context. Another electronic learning system, proposed in [26], suggests educational concepts and learning materials considering student performance, learning style, and progress; in this system, the professor has access to see performance, progress, objectives, and playlists from the student. On the other hand, the mobile application presented in [27] based on multiple questions, determines the initial set of learning objects that will be downloaded locally for English language learning and identifies the student's progress and comparing it with that of others classmates.

\section{$3 \quad$ Materials and Methods}

We develop the proposed platform following the ICONIX methodology [31]. In this regard, the work was divided into three main stages:

- Stage 1: Development of services for learning monitoring and reinforcement.

- Stage 2: Development of services for learning customization.

- Stage 3: Platform assessment based on two approaches.

In the first evaluation approach, we performed a qualitative comparison between the platform proposed in this work and the solutions offered in the specialized literature. On the other hand, in the second evaluation approach, usability assessment of the 
SiGOAM was carried out to measure the satisfaction criterion from the professor's point of view and obtain feedback that would improve the services offered by SiGOAM. According to the guidelines of the ISO/IEC 25010 usability standard [29], the satisfaction aspect of the teaching users was assessed by applying the QUIS 7.0 questionnaire [30].

In stages 1 and 2, four steps were carried out and are described below:

- Step 1: Requirements analysis: the initial specification of functional requirements that are part of our platform was generated, and the use case diagrams were developed.

- Step 2: Analysis and design: the use case specification, a relational diagram, a prototype of the non-functional GUI (user interface), and the component diagram were developed.

- Step 3: Implementation: In this step, the programming of the services was carried out.

- Step 4: Integration and unit tests: In this last step, the integration and unit tests were carried out to validate the correct performance of all components of the proposed platform.

Below, the general description of the platform is given, also the use case diagram, and the relational data model.

\subsection{Platform overview}

The platform proposed in this work is composed of three components, which provide different services for the learning monitoring and customization:

1) A mobile learning object generator system (SiGOAM)

2) A mobile learning object repository (MLOR)

3) A mobile application (AppMo), see Figure 1.

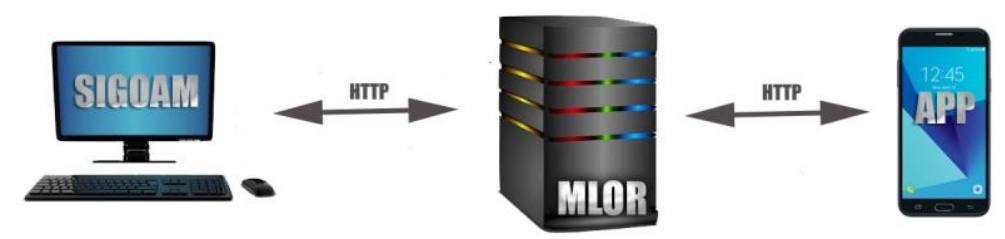

Fig. 1. Platform components

SiGOAM offers the professor multiple services grouped into four modules to generate quality MLOs: Analysis, design, development, and product-oriented tests. The analysis module allows the professor to obtain a guide for the acquisition of information and the production of the activities composing the MLO. In the design module, the professor can esthetically build the educational content obtained in the analysis module. On the other hand, the development module allows the professor to generate a functional MLO prototype. Finally, in the module of product-oriented tests, 
the professor can assess the technological, pedagogical, and usability aspects of the MLO to obtain feedback from the students and improve it. The learning objects generated by SiGOAM have the following general structure: Introduction, lessons, examples, exercises, and evaluations. The MLOR component allows us to store, catalog, consult, and visualize MLOs generated by SiGOAM, as well as classifying MLOs according to the learning style and context defined by the professor when built them. The MLOR also allows the professor to monitor every mobile learning object consulted by students, including the time invested in each of them. Finally, the mobile application (AppMo) allows the student to consult, view, interact, and recommend MLOs based on their learning style and specific context. In the following subsections, the learning monitoring and customization services of our platform are detailed.

\subsection{Case uses diagram}

The use case diagram models the functions of the platform in terms of learning monitoring and customization services. Two types of actors are involved in these services:

Professor: This type of user oversees providing learning objects, based on the learning styles and context of the students; monitors the learning progress of students; and reviews the learning objects studied and the time invested by students.

Student: The central services of this type of user comprise answer the CHAEA questionnaire [28] to define their predominant learning style, consult, visualize, evaluate, and recommend learning objects added to each group that the student belongs.

Services offered by the proposed platform are depicted in two use case diagrams: one displays the services offered by the mobile learning objects repository (Figure 2), and another presents the services provided by the mobile application to students (see Figure 3 ). The use cases of the MLOR describe the system operation to allow professors to monitor the learning of students:

- UC01-01 Register new group: Describes the process to add a new group.

- UC01-02 Add student to group: Establishes the process to assign students to a previously created group.

- UC01-03 Add category to group: Defines the process to assign a category to a previously created group.

- UC01-04 Add MLOs to categories: Describes the steps to add learning objects to a category.

- UC01-05 Consult studied MLOs: Describes the process of consulting the learning objects studied by students.

- UC01-06 Suggest MLO for reinforcement: Describes the steps to recommend a learning object to a specific student to reinforce a studied topic.

- UC01-07 Complete MLO publication: Describes the process to complete the publication of learning objects uploaded through the SiGOAM. 


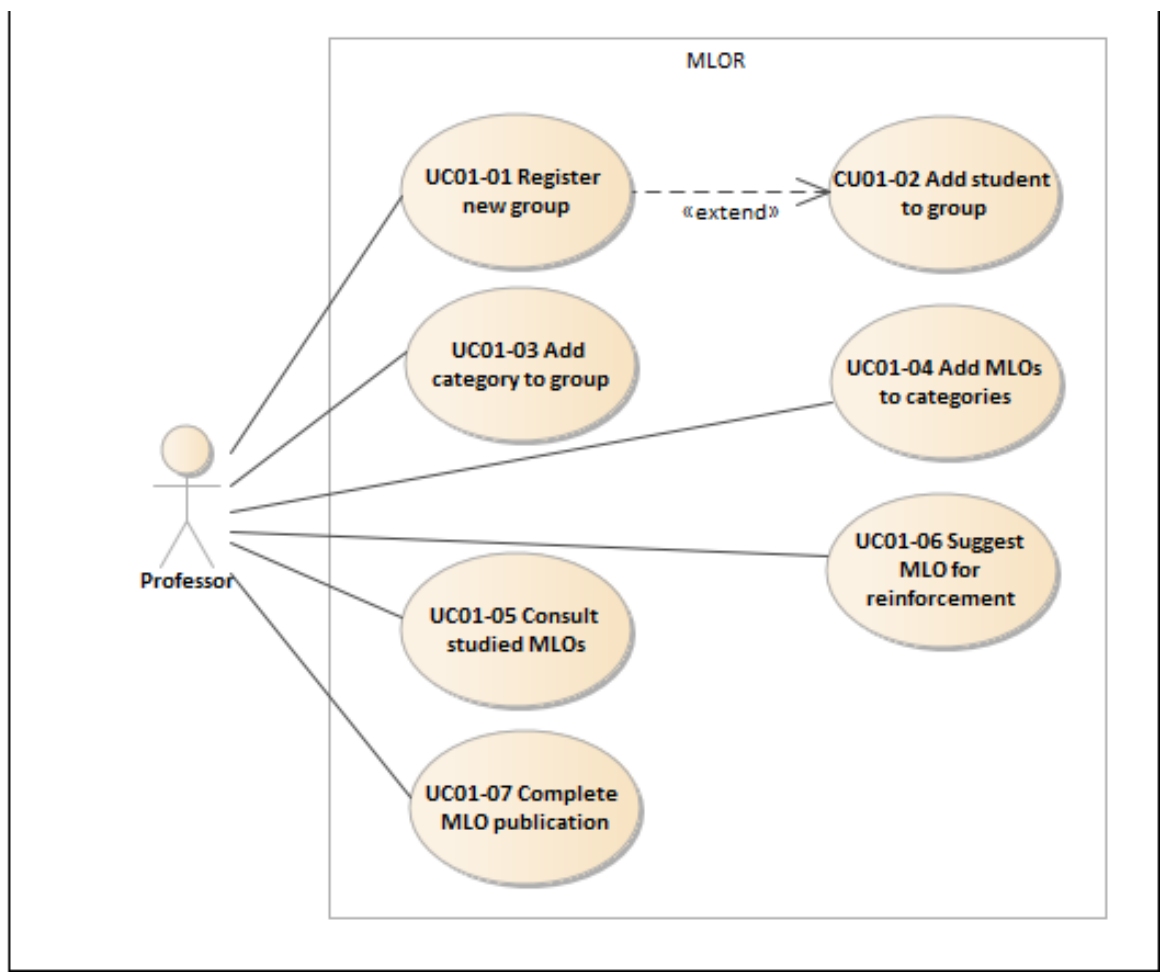

Fig. 2. Use case diagram of MLOR

Figure 3 shows the use case diagram, which presents different functionalities of the mobile application, in order to customize student learning, based on their learning style and context (referring to whether the student mobile device is in motion or at rest). In this regard, the use cases of the mobile application are listed and described below:

- UC02-01 Answer CHAEA questionnaire: Describes the steps to define the student learning style on the platform.

- UC02-02 View groups and categories: Defines the process to visualize the groups in which the student is enrolled, as well as the categories belonging to each group.

- UC02-03 Consult studied MLO: Establishes the process to be followed by the student to consult the list of learning objects he/she has previously studied.

- UC02-04 Consult added MLOs: Describes the process for the student to consult the list of learning objects that the professor has uploaded to a group.

- UC02-05 Consult reinforcement MLOs: Establishes the steps that the student must follow to consult the learning objects recommended by the professor to reinforce a topic.

- UC02-06 Consult recommended MLOs: Describes the process of recommending learning objects based on the student's context and learning style. 
- UC02-07 View learning object: Describes the process of viewing learning objects, where the student can interact and navigate through the sections of the MLO.

- UC02-08 Assess MLOs: Describes the process of evaluation of learning objects by students.

- UC02-09 Consult professors: Describes the process to check the list of professors of the student.

- UC02-10 Send email: Describes the process for students sends an email to professors through the platform.

- UC02-11 Consult learning styles: Describes the process to check the score obtained in the learning styles questionnaire.

- UC02-12 Create user account: Describes the student functionality to create a user account on the platform.

- UC02-13 Modify user account: Describes the process to modify the student's user account data.

- UC02-14 Set preferences: Describes the process to set student preferences concerning recommendations of learning objects based on his/her learning style and context.

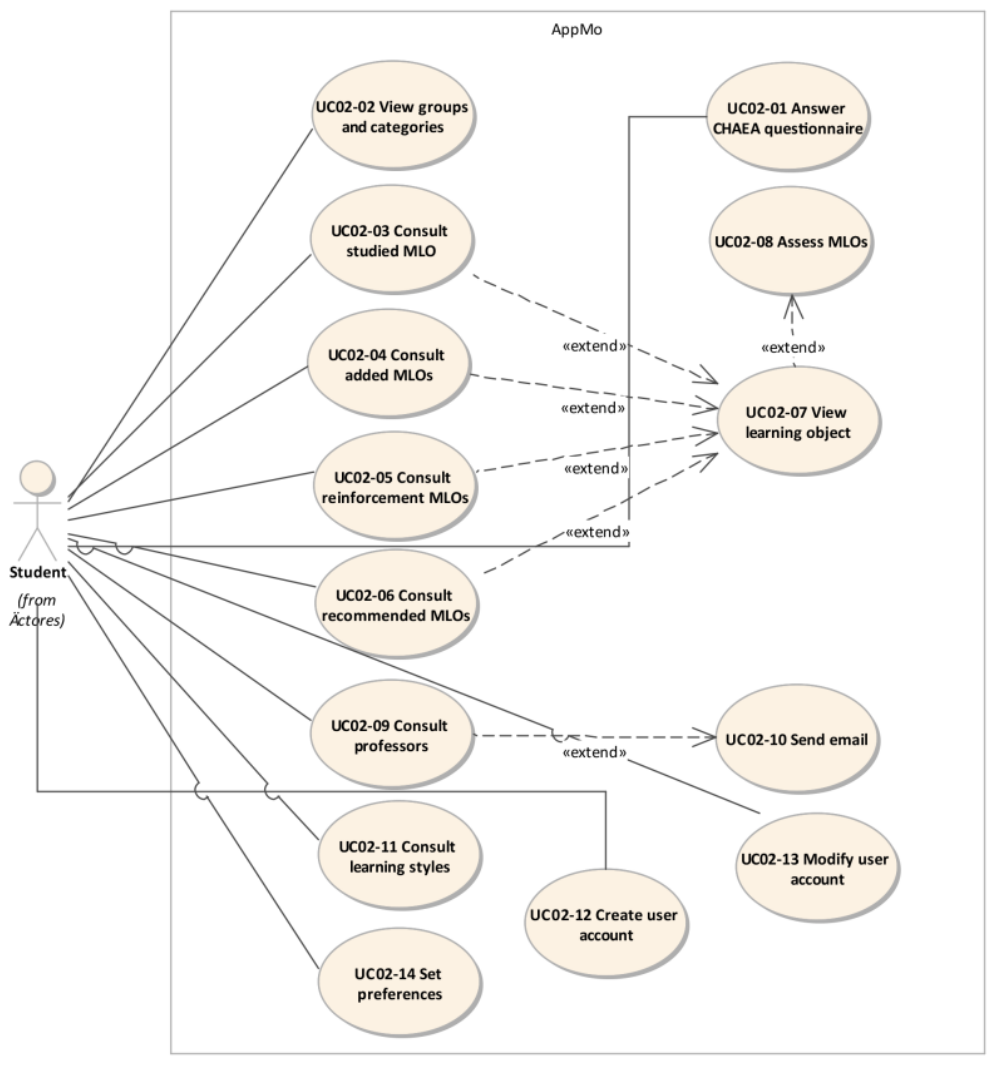

Fig. 3. Use case diagram of mobile application 


\subsection{Relational data model}

The relational data model presented in this section describes the structure of our platform's database and the type of data that will be stored in tables and their relationships. The data model corresponds to the MLOR (Figure 4) in which information regarding the learning monitoring and customization (groups, categories, learning styles, etcetera) is stored, as well as the information about learning objects. The data model possesses a total of 16 tables which are listed below:

- Learning_objects: Stores the metadata of learning objects

- Categories: Allows classifying learning objects

- Learning_objects_categories: Relationship table between learning objects and categories.

- Formats: This table stores formats of learning objects

- Key_words: Stores keywords that allow identifying learning objects

- Key_words_learning_objects: Relationship table between learning objects and keywords

- Comments: Stores students' comments about learning objects

- Users: This table stores the registered users on the platform

- Roles: It stores user roles for access to the platform (administrator, student, and professor)

- Downloads_users: This table records the downloads of learning objects performed by students

- Learning_objects_recommended: This table stores the learning objects recommended by professors to students

- Learning_objects_assessment: This table stores the score assigned by students to learning objects regarding how useful the learning object was to understand the studied topic

- Score: It stores the number of views that the learning object has per student, as well as the total time invested. The table includes the score field in order to develop a future service

- Student_learning_profile: Stores the results of the learning styles questionnaire answered by students

- Groups: It stores data concerning the groups created by professors

- Groups_users: This table is used to manage the relationship between groups and users 


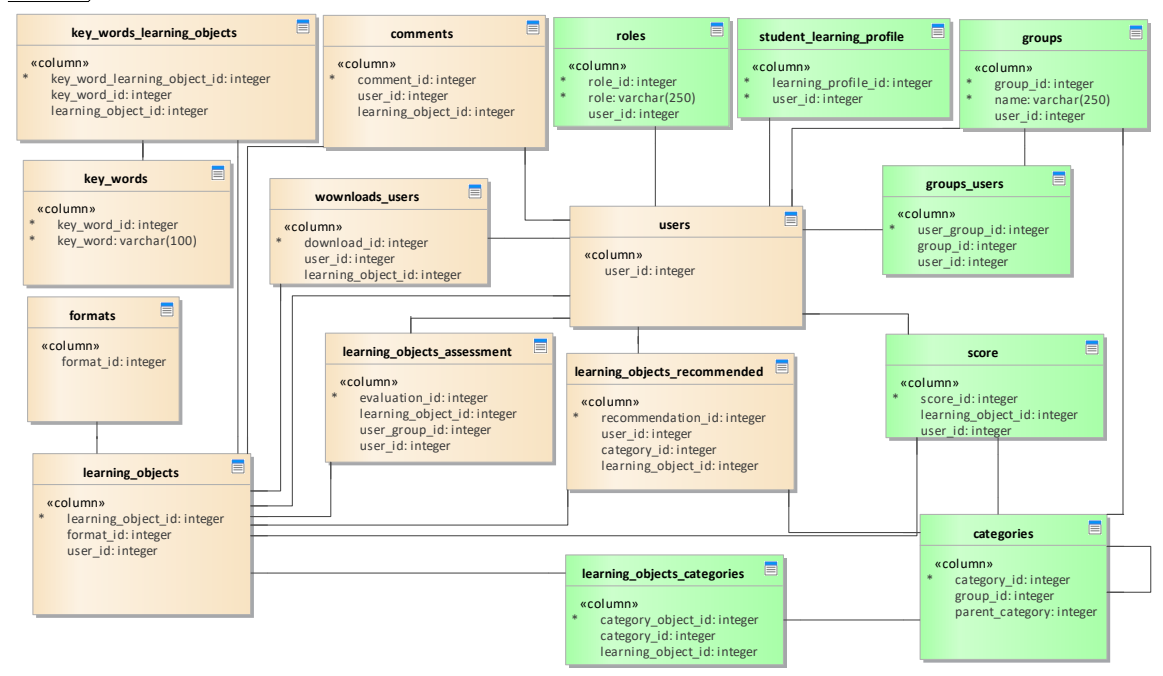

Fig. 4. Relational data model

\section{$4 \quad$ Results}

This section describes the platform services development based on a formal architecture. The following elements are described in detail below: Component diagram, SiGOAM services, monitoring and learning customization services.

\subsection{Component diagram}

The component diagram presented in Figure 5 shows the interconnections among SiGOAM, MLOR, and the Android application; moreover, it depicts all the systems components and their relationship. SiGOAM and MLOR were designed based on the Model-View-Controller (MVC), which is a pattern for web applications development [32]. MVC separates the business logic from the user interface, promoting its evolution separately to increase the reuse and flexibility. As shown in Figure 5, the technologies adopted for the View were HTML, JQuery, and Angular, which makes requests to the Spring MVC controller [33]. These requests are executed through Web services (RESTful) connected through objects to the Spring entities, which apply Data Access Objects (DAO) connection entities. DAOs are connected to the database model in PostgreSQL by means of the Java Persistence API (JPA). Spring is a Java enterprise application development framework designed to make development more agile and fast, with a minimal initial configuration, whose main features include: Dependency injection, data access, transaction management, batch data processing, and security. 


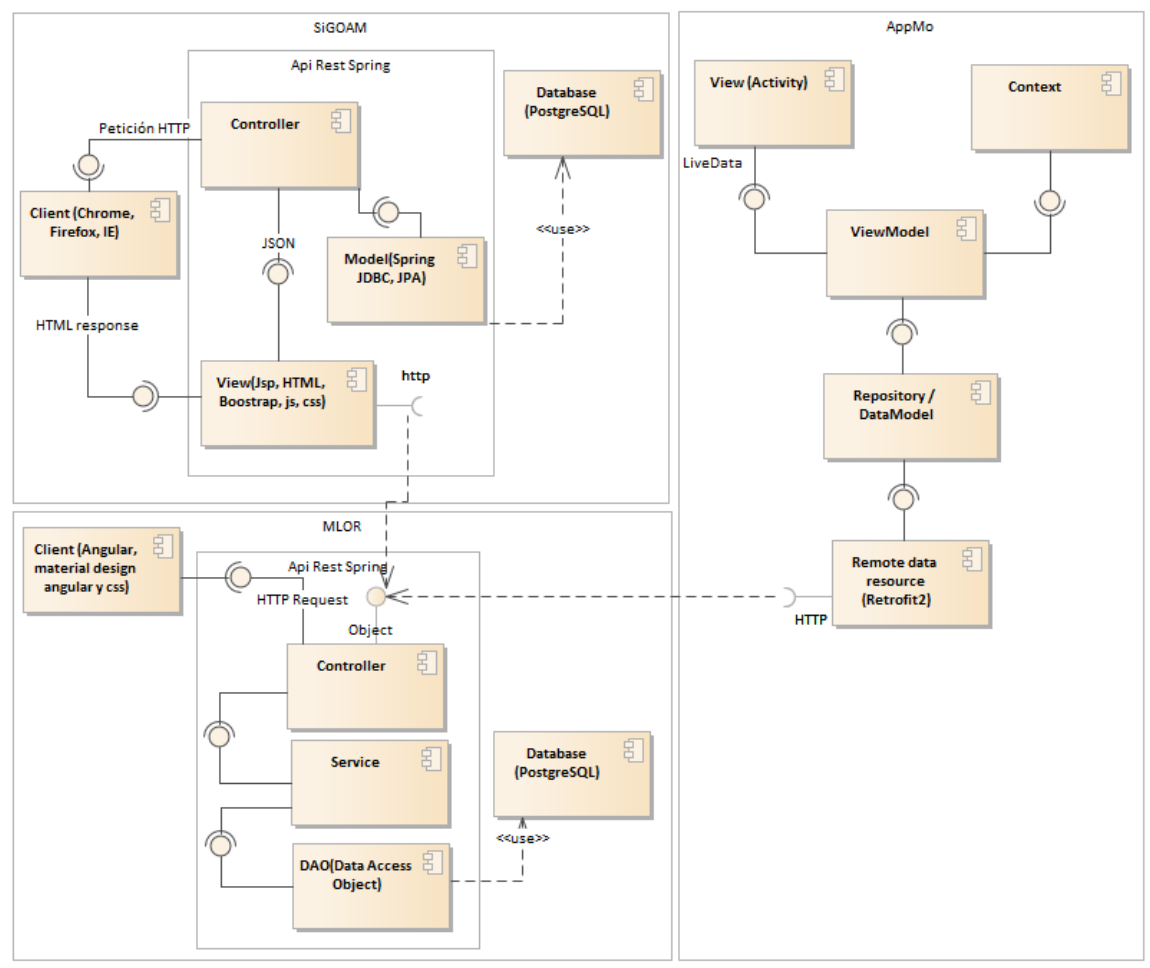

Fig. 5. Component diagram

The component diagram for the mobile application is based on the architectural pattern Model View ViewModel (MVVM), which is recommended in the Android developer documentation [34]. The advantages of the MVVM include:

- Reuse of code and functionalities

- Simplification of tests

- Separation of responsibilities

- Decoupling the behavior of the model with the view

\subsection{SiGOAM services}

The services for the creating of mobile learning objects provided by SiGOAM to the professor are distributed in four modules: analysis, design, development, and product-oriented tests. In the analysis module, the professor adds the content and resources (images and videos) to be used during the learning object's construction process, which is structured in lessons, examples, exercises, and evaluation. Figure 6 shows one of the interfaces that allow the professor to consult and add the content and resources that integrate the mobile learning object. 


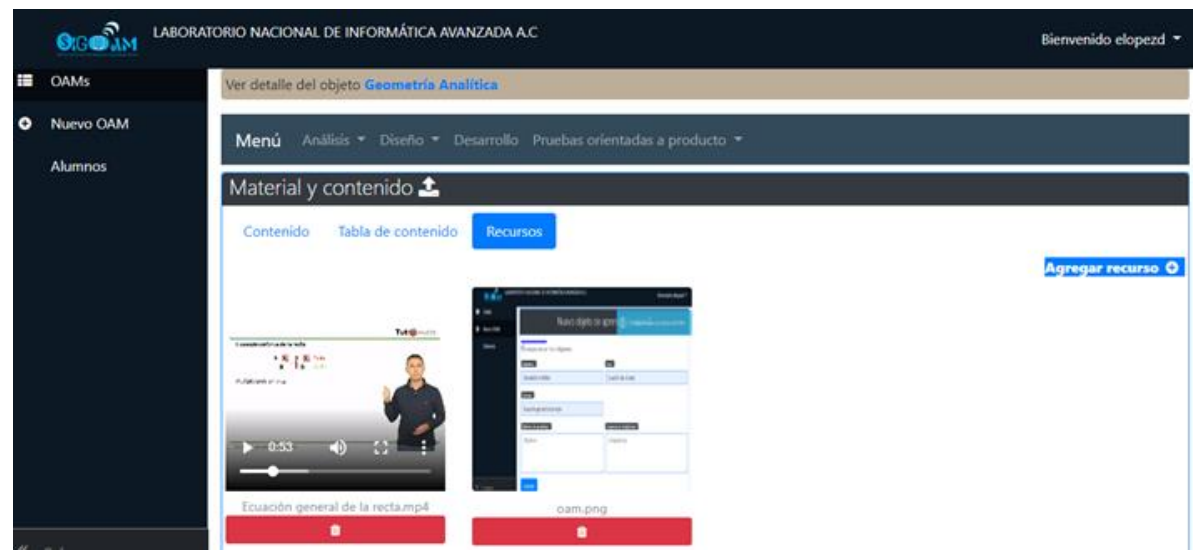

Fig. 6. Interface to consult and add resources

On the other hand, in the design module, the professor is provided with different services that allow him/her to structure, visualize, format, among others, the content added to the MLO in the analysis module. Figure 7 shows an example of the interface that allows formatting (such as learning type, color, and alignment) to the lesson's information concerning the learning object.

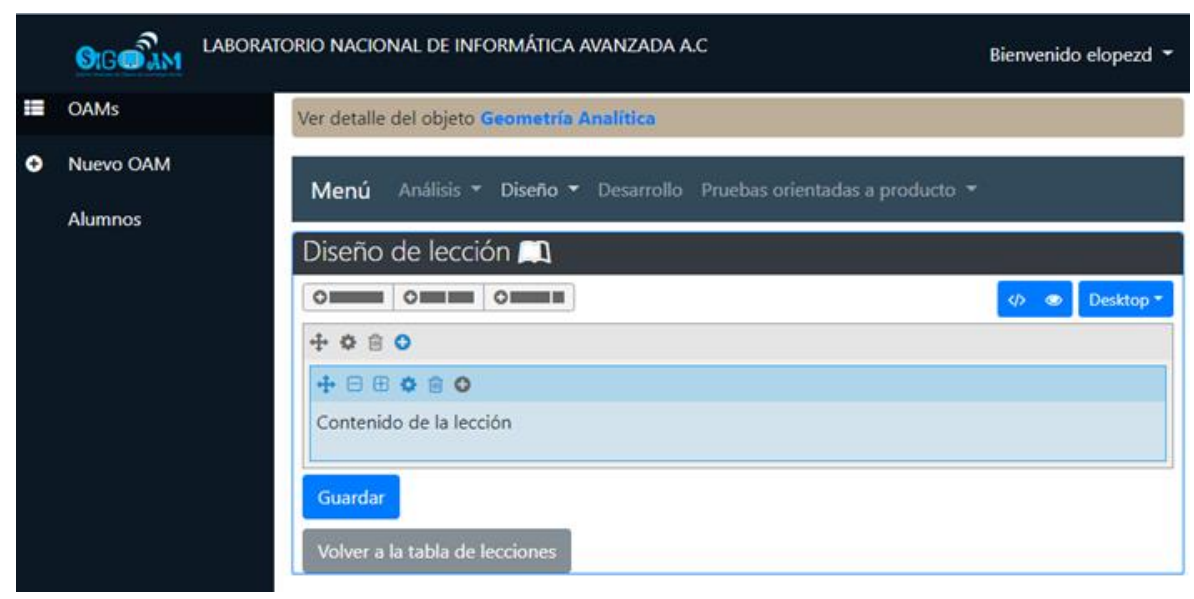

Fig. 7. Interface of the design lesson service

In the development module, SiGOAM allows the professor to automatically build their mobile learning object with the contents registered and designed in previous modules to finally download or publish it in a mobile learning objects repository, see Figure 8. 


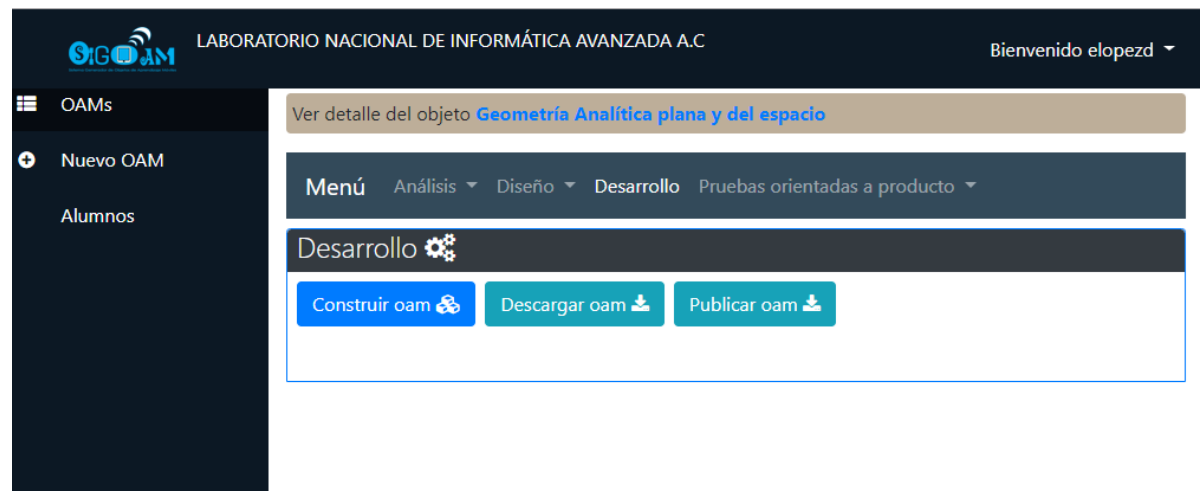

Fig. 8. Interface of the development stage

Finally, once the learning object is published in the repository, the student can view it from the mobile application (Figure 9), either through a recommendation of the application or through a student search. Each time a student visualizes a learning object, the time invested is stored. Furthermore, the application records the number of times a student studies a learning object.

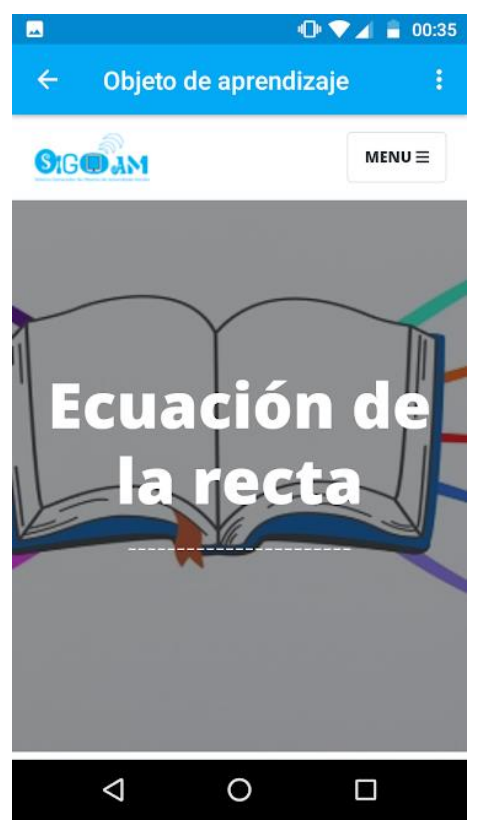

Fig. 9. Learning object from the mobile application 


\subsection{Services focused on the learning monitoring}

Learning monitoring services allow the professor to consult learning objects studied by their students, as well as the time they invested and the times they consulted a learning object. Moreover, our platform allows the professor to recommend learning objects to reinforce a topic that could be difficult for students. The visualization of learning objects studied by students is accessed from the mobile learning objects repository, see Figure 10.

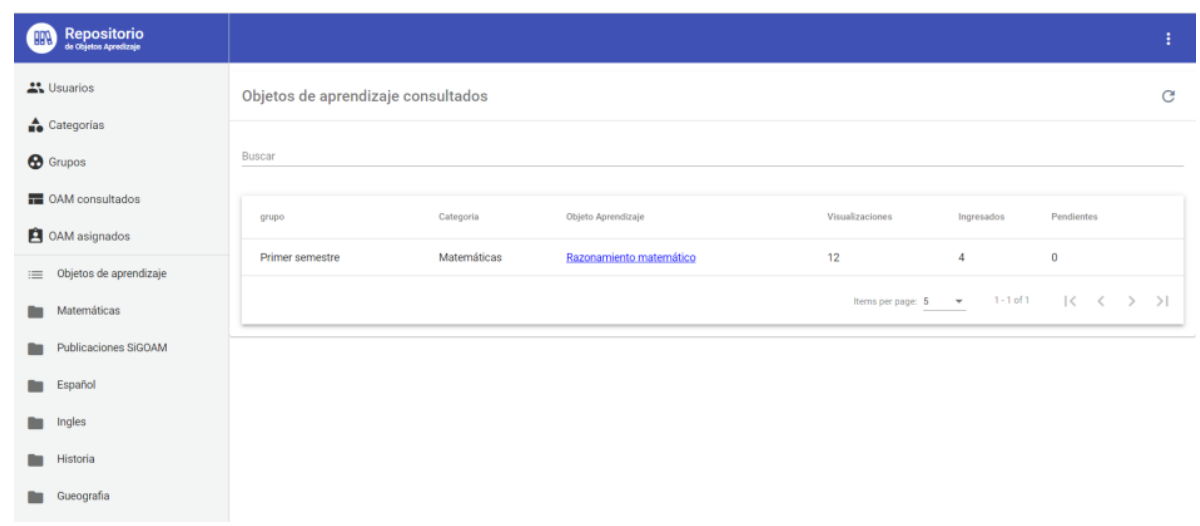

Fig. 10. Learning objects studied

Figure 11 shows the interface that allows the professor to visualize the list of students who studied a specific learning object, as well as the total time students have invested in the learning object, and the number of times they have accessed it.

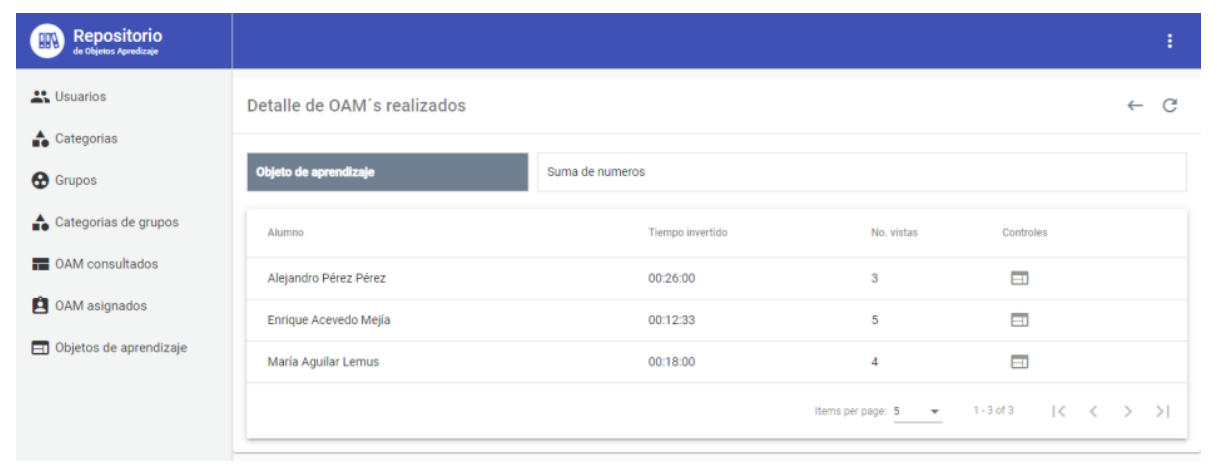

Fig. 11. Detail of learning objects studied

Concerning the recommendation of MLO by the professor for the reinforcement of a topic that could be difficult for students, a service was developed that allows the professor selecting a learning object, as well as the list of students to whom the MLO would recommend, see Figure 12. 


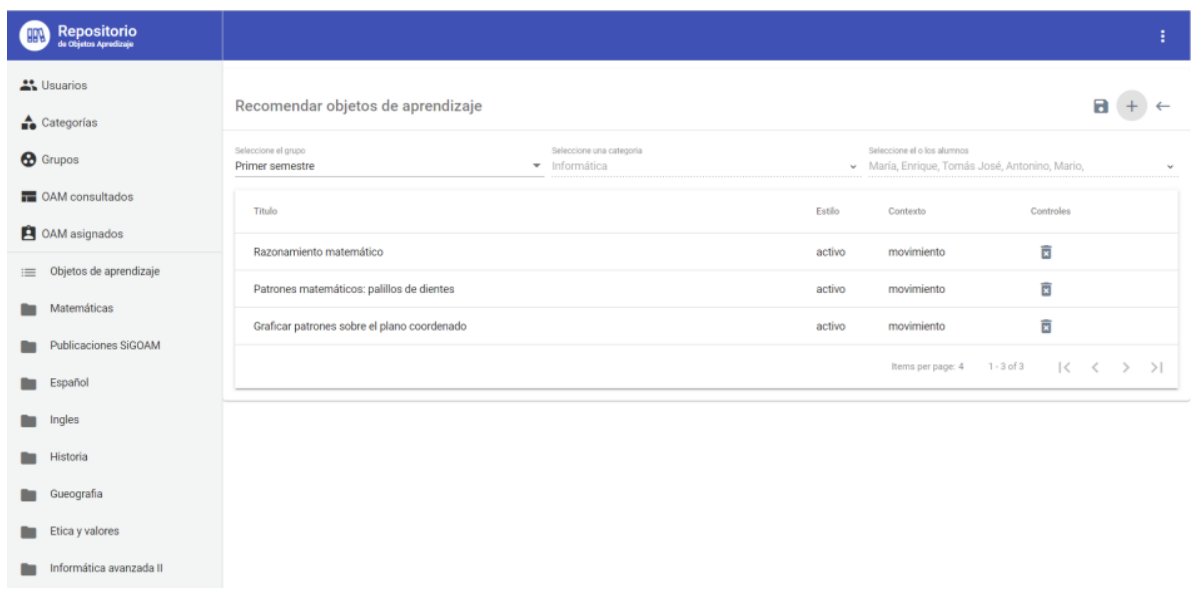

Fig. 12. Learning objects for reinforcement

\subsection{Services focused on the learning customization}

Learning customization services are provided to students through the mobile application and include: Obtain the physical activity of students, define learning styles, visualize learning styles, recommend learning objects according to the learning style and physical activity of students, as well as the recommendation of learning objects evaluated by other students with similar learning styles. The sensors of the mobile device are used to obtain the physical activity of students. The Application obtains the following activities: Static, standing, walking, running, cycling, vehicle, and lying down, then classifies them at rest or in motion. Additionally, in order to identify the student's learning styles, the Honey-Alonso questionnaire [28] was implemented, which considers the following styles: active, reflective, theoretical and pragmatic. The application allows visualizing the predominant learning styles in students at any time. Based on the physical activity and the predominant learning styles of the student, the application recommends the learning objects related to the student (Figure 13). For example, if a student is moving, ideally, the application recommends learning objects that do not involve lessons in which the student has to read text on the screen. Therefore, the application will recommend learning objects that include videos and audios.

The application also allows students to evaluate learning objects, considering how useful it was for them to understand the studied topic. For the learning object assessment, a scale of 1 to 5 was taken, where extreme values ( 1 and 5) denote a very bad, and very good usefulness, respectively. Based on the assessment performed by students, the application recommends learning objects to other students with similar learning styles, see Figure 14. This type of recommendation supports the student since they only receive recommendations regarding student's perceptions who learn in the same way. For example, suppose a student positively assesses a learning object that is designed for an active learning style. In this case, the learning object is more likely to be more useful for students who have an active learning style than those with a theoretical, pragmatic or reflexive learning style. 


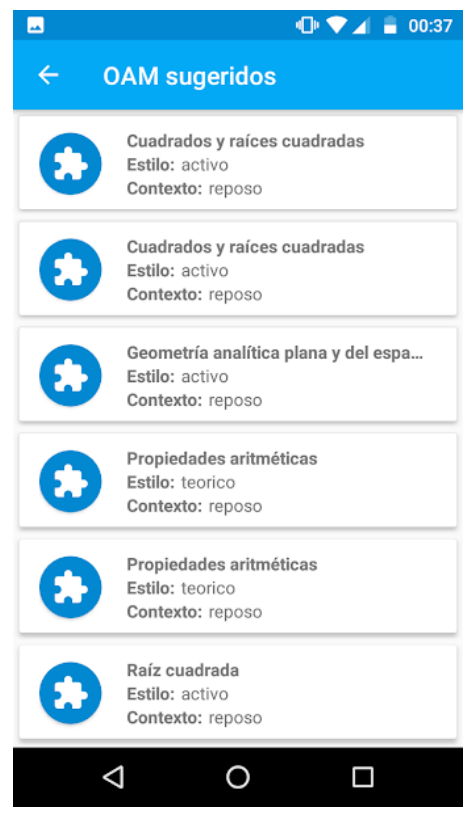

Fig. 13. Recommended learning objects by application

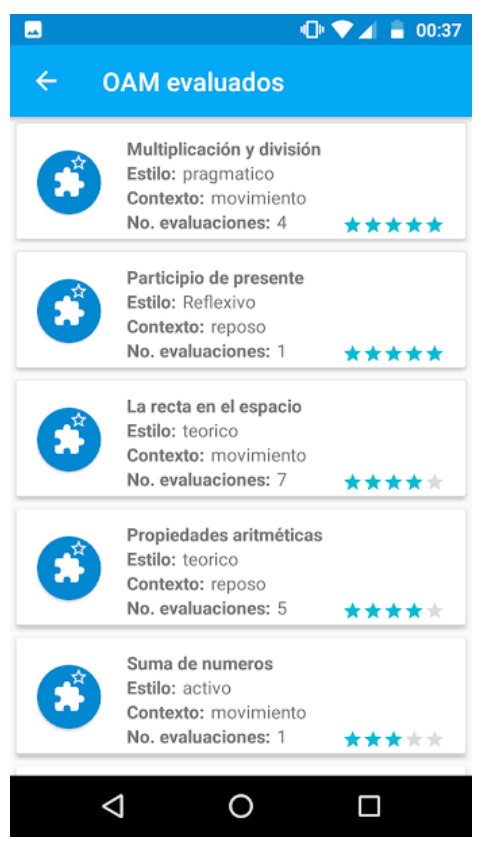

Fig. 14. Recommended learning objects by students 
Tests carried out had the aim to verify the expected behavior of services provided by the platform. Various iterations were carried out to ensure that the monitoring and customization services work correctly. The errors found during the testing process were solved, and new iterations were performed to confirm the correct operation.

\section{Platform Assessment and Discussion}

This section describes two evaluations carried out on our platform. In the first evaluation approach, we performed a qualitative comparison between the platform proposed in this work and the solutions offered in the specialized literature. On the other hand, in the second evaluation approach, usability assessment of the SiGOAM was carried out to measure the satisfaction criterion from the professor's point of view and obtain feedback that would improve the services offered by SiGOAM.

\subsection{First evaluation approach: Qualitative comparison}

Based on a review of the state-of-the-art presented in Table 1, some works have features that allow learning monitoring; others support learning customization based on student's preferences and abilities, and a reduced group of works presents approaches that enable both, learning monitoring and customization, see Table 1.

Table 1. Qualitative comparison of related works

\begin{tabular}{|c|c|c|c|c|c|c|c|c|c|c|c|c|c|c|c|}
\hline \multicolumn{16}{|c|}{ Services of learning customization } \\
\hline $\begin{array}{l}\text { Related works } \\
\text { Services }\end{array}$ & [13] & [14] & [15] & [16] & [17] & [18] & [19] & [20] & [21] & [22] & [23] & [24] & [25] & [26] & [27] \\
\hline Consider student performance. & $\checkmark$ & $\checkmark$ & $\checkmark$ & & $\checkmark$ & & $\checkmark$ & & & & & & & $\checkmark$ & $\checkmark$ \\
\hline Consider student preferences. & $\checkmark$ & & $\checkmark$ & $\checkmark$ & $\checkmark$ & & $\checkmark$ & & & & & & & $\checkmark$ & $\checkmark$ \\
\hline Consider learning styles. & & $\checkmark$ & $\checkmark$ & $\checkmark$ & & $\checkmark$ & & & & & & & $\checkmark$ & $\checkmark$ & $\checkmark$ \\
\hline Consider the context of the student. & & $\checkmark$ & & & $\checkmark$ & $\checkmark$ & & & & & & & $\checkmark$ & & \\
\hline $\begin{array}{l}\text { Suggest content that was useful for other } \\
\text { students. }\end{array}$ & & & $\checkmark$ & & & & $\checkmark$ & & & & & & & & $\checkmark$ \\
\hline \multicolumn{16}{|c|}{ Services of learning monitoring } \\
\hline It lets demonstrating what has been learned. & & & & & & & & $\checkmark$ & & & $\checkmark$ & $\checkmark$ & $\checkmark$ & $\checkmark$ & $\checkmark$ \\
\hline It monitors on the activities carried out. & & & & & & & & $\checkmark$ & $\checkmark$ & $\checkmark$ & $\checkmark$ & $\checkmark$ & $\checkmark$ & $\checkmark$ & $\checkmark$ \\
\hline It provides student progress information. & & & & & & & & & $\checkmark$ & & $\checkmark$ & & & $\checkmark$ & $\checkmark$ \\
\hline It provides feedback. & & & & & & & & & & $\checkmark$ & $\checkmark$ & $\checkmark$ & & & \\
\hline $\begin{array}{l}\text { It has services that reinforce the learning of } \\
\text { a topic. }\end{array}$ & & & & & & & & & & & & & $\checkmark$ & $\checkmark$ & \\
\hline
\end{tabular}

Most studies that provide learning customization services use some mechanism to obtain student learning styles, except for the work presented in [13], [17], [27]. In these works, students answer some questions where they indicate what type of content they want to receive. Nevertheless, none of the works that consider learning styles, contemplate the fact that the predominance towards a learning style can change 
throughout the student's learning process, this could cause the systems at some point to stop providing appropriate content to the student.

Moreover, the implementation of contextual data acquisition of the student is only carried out by systems proposed in [14], [17], [18], [25], which use the GPS sensors and accelerometer. However, these works only focus on checking if the device detects any movement or if the user is moving, but the possible activity performed by the student is not determined, such as: At static, walking, by car; which is essential to specify the type of content that must be provided to the student.

Concerning learning monitoring services, all reported systems allow users to consult the activities carried out by the students, as well as their performance. Only in the system proposed in [26] suggest new content if the student's performance is low. On the other hand, none of the reviewed works store a history of the times the student made use of the learning object, and the time spent; this information is required for estimating the progress of student learning.

According to the review of the related works, there is a marked separation of services to which the proposed systems were focused, for example, some works include in their architecture tools for creating educational resources, others consider repositories for storage, and in general, all the reviewed works include an application that allows the visualization of the contents. However, none of the works have an architecture that considers the three components integrated within a single platform. Therefore, our platform has a set of advantages, including:

- It considers learning styles while incorporating mechanisms to obtain students' physical activity to provide recommendations of learning objects related to student preferences and conditions.

- It provides recommendations of learning objects that were useful to other students with equal or similar learning styles.

- It allows the monitoring of the studied learning objects by students.

- It integrates three tools in a single platform: a mobile learning object generator system, a mobile learning object repository and a mobile application; which allows carrying a complete flow from when the professor designs and creates a mobile learning object, until the student consults it from a mobile device, and subsequently obtains feedback and self-assessment.

\subsection{Second evaluation approach: SiGOAM usability assessment}

We carried out a usability assessment of SiGOAM proposed in this work based on a field study with 5 graduate-level professors. To achieve evaluation, first, professors were trained in the use of the different services of SiGOAM. Subsequently, they were asked to perform an MLO individually related to their course. Finally, according to the guidelines of the ISO/IEC 25010 usability standard [29], the aspect of user satisfaction was assessed by applying the QUIS 7.0 questionnaire [30]. This section presents the instrument's description, a description of the field study, and the obtained results. 
Description of the instrument. QUIS questionnaire version 7.0, developed by the University of Maryland [30], was used to measure the satisfaction of the participating professors. The questionnaire consists of thirty-two questions grouped into six evaluated categories:

- Global reaction to the system: It includes questions to know the user's perception regarding utility, flexibility, ease of use, among others.

- Screen: These questions are aimed at evaluating screen features such as typography, design, distribution, and sequence.

- System terminology and information: It assesses whether the terms used by the system help the user reach his/her goal and if there is consistency in the positioning and content of messages.

- Learning: It collects information related to the ease with which the user learns to use the software.

- System capabilities: It allows knowing the performance and recovery before committed errors by the user.

- Ease of use and user interface: It assesses general aspects of the software interface design.

In this instrument, the Likert scale selected for each question consists of 9 conceptual levels of satisfaction: 0-9 where 0 is the lowest grade and 9 the highest. The answers obtained by this instrument are analyzed by the average per category and the overall average. The acceptability ranges are defined as follows:

$$
\begin{gathered}
0 \leq \text { satisfaction } \leq 3 \text { : Unsatisfactory } \\
4 \leq \text { satisfaction } \leq 6 \text { : Acceptable } \\
7 \leq \text { satisfaction } \leq 9 \text { : Satisfactory }
\end{gathered}
$$

Based on these ranges, if the overall average achieved is between 0 and 3 , it means that professor satisfaction with the mobile object generating system (SiGOAM) is unsatisfactory. Otherwise, if the general average obtained is between 7 and 9, it means that the satisfaction of professors concerning SiGOAM is satisfactory.

Description of the field study. The experiment was carried out at the National Laboratory of Advanced Informatics (LANIA), Mexico, with the participation of five research professors of different disciplines, three of them with doctoral-level studies and two with a master's degree. Before the experiment began, the participant professors received training in the use of SiGOAM with a duration of approximately one hour. In this span of time, we worked on guided practices for the construction of an MLO. The experiment lasted nearly two months, where professors worked individually in the creation of an MLO. At the end of the construction of the MLO, the questionnaire for user satisfaction (QUIS 7.0) was applied to register professors' opinion regarding their overall reaction to the system, the screen, the terminology and information of the system, learning, system capabilities, and usability, as well as graphical user interface.

Satisfaction results. Based on the QUIS 7.0 answers, the satisfaction score average per professor and category were calculated. Finally, the overall average of the instrument was determined to measure the satisfaction level of all participating professors. In this regard, the means for each category were summed and divided by the 
number of categories, see Table 2 . The results obtained by each category are presented below.

Global reaction to the system: In this category, two users obtained an average greater than six, while three had a result less than four. Based on the acceptability scale defined for instrument QUIS 7.0, this category is rated as acceptable. Therefore, it is concluded that the teachers in general had an acceptable reaction in this category.

Screen: The overall average for this category was 5.7, which is classified as acceptable. Taking into account the feedback of the users, points of improvement were identified in the representation of characters since in some screens there were problems with the display of punctuation marks; multimedia content such as images and video were overflowing, and the content of some sections was confusing.

Table 2. Results of QUIS 7.0

\begin{tabular}{|l|c|c|c|c|c|c|}
\hline \multicolumn{1}{|c|}{ Category } & User 1 & User 2 & User 3 & User 4 & User 5 & Average \\
\hline Global reaction to the system & 6.2 & 6.0 & 3.8 & 2.5 & 5.5 & 4.8 \\
\hline Screen & 7.0 & 7.0 & 5.0 & 2.5 & 7.0 & 5.7 \\
\hline Terminology and system information & 6.5 & 7.3 & 5.0 & 1.3 & 6.7 & 5.4 \\
\hline Learning & 6.7 & 5.3 & 2.2 & 3.0 & 6.5 & 4.7 \\
\hline System capabilities & 6.8 & 7.0 & 3.6 & 1.2 & 6.6 & 5.0 \\
\hline Usability and user interface & 5.6 & 6.6 & 5.6 & 1.4 & 6.8 & 5.2 \\
\hline Total & \multicolumn{7}{|l}{} & & 5.1 \\
\hline
\end{tabular}

Terminology and system information: Based on the results obtained in this category, the participants considered that the terminology and information provided by the system regarding the task performed are acceptable. Points for improvement were also identified, such as the terms used in the exercises and evaluation sections, since the abbreviations that define the type of exercise were neither descriptive nor clear.

Learning: The overall average obtained for this category was 4.7 , which is classified as acceptable. In this category, it was identified that the navigation menus had to be improved since their design was confusing to the user.

System capabilities: According to the results obtained in this category, users perceived that aspects such as response speed, error correction, and ease of reaching their goals with the system are acceptable. Regarding the improvement points, it was identified that the file upload was slow.

Usability and user interface: In this category, four users obtained an average greater than five, the highest being 6.8 while only one user obtained 1.4. Based on this, points of improvement were identified in all the interfaces of the system, since they presented inconsistencies in the design of forms, buttons, distribution, and presentation of content, among others. The overall average for this category was 5.2, which is classified as acceptable.

Based on the described results, the overall average is calculated to measure the level of satisfaction of all users:

$$
\text { Satisfaction }=\frac{4.8+5.7+5.4+4.7+5.04+5.2}{6}=5.1
$$


Therefore, user satisfaction is considered acceptable. Finally, and according to the analysis carried out in [35], the number of users who participated in our study allowed us to identify probably around $80 \%$ of the usability problems of SiGOAM. The usability problems identified in our study were corrected.

\section{$6 \quad$ Limitations}

Our work has some limitations in terms of validity concerns. The main limitations are that only our mobile learning object generator system (SiGOAM) has been assessed in a real work environment with 5 graduate-level professors; eventually, we will carry out a complete usability assessment of the platform considering the MLOR and AppMo, and our study lacks pedagogical data that allow us to determine the impact of the mobile learning platform in the teaching-learning process. It should be emphasized that the assessment of the pedagogical dimension implies a more complex analysis; which is subject to different variants, so it was not within the purpose of this work. Nevertheless, considering the three-level evaluation framework proposed by Vavoula and Sharples [36], the usability features of mobile learning systems, being at the lowest level, influence at higher levels within which they are found aspects related to the learning experience.

\section{Conclusions and Future Work}

This paper presented the analysis, design, and development of a mobile learning platform aimed at learning monitoring and customizing of university students through mobile learning objects (MLOs). Our platform differs from other proposed by integrates a mobile learning object generator system (SiGOAM), a mobile learning object repository (MLOR), and a mobile application, which recommends and presents learning objects to students. The integration of these three elements in a single platform supports the professor to implement various strategies for learning monitoring and customizing systematically. From our point of view, the most important platform's advantages are the following:

1) Provide various services to the professors to construct high quality MLOs

2) Distribution of massively constructed MLOs among students through specialized MLOR for this type of digital resources

3) Considers student learning styles while incorporating mechanisms to obtain the possible activity carried out by students (at rest or on the move), to provide recommendations of mobile learning objects suitable to students' circumstances, skills, and preferences

4) Provide recommendations of learning objects that were useful to other students with equal or similar learning styles

5) Allow the professor to monitor the student learning concerning the consulted MLOs, visualize the times the student accessed it, and the total time spent 
On the other hand, in this work, a preliminary usability assessment of SiGOAM was carried out to measure satisfaction in six categories based on a field study with 5 graduate-level professors. In our work, the aspect of user satisfaction was assessed by applying the QUIS 7.0 questionnaire. According to the obtained results, the learning object generator system presents a good acceptance, satisfaction, and applicability from the professors' perspective. Both QUIS results and the professors' feedback were considered to generate an enhanced SiGOAM version. In this regard, the most significant changes were performed in the user-interfaces features, such as: Navigation menus, messages displayed, the terminology used in the system, special characters encoding, the preview of multimedia resources, visualization of the MLO construction stages, and design of the created MLO. Finally, the metadata register form was enriched with indications about the information that the user should capture. Considering the results and products obtained from this work, several lines of research are open allowing the continuity of different future work, including:

1) Extending the monitoring services of the platform to show statistics of the student's progress or evolution in the different groups to those that belong

2) Add a recommendation service, which considers the student's performance to suggest learning objects that help reinforce the studied topics

3) Add the offline functionality in the mobile application that allows saving the data locally if the user does not have access to the Internet, and when a connection is detected, the system updates the information on the server automatically

4) Carry out a usability assessment of the MLOR and the student-oriented mobile application based on a field study.

\section{$8 \quad$ References}

[1] R. Santiago, S. Trabaldo, M. Kamijo, and Á. Fernández, Mobile Learning: Nuevas realidades en el aula. España: Océano S.L.U., 2012.

[2] C. Castillo valero, M. Roura Redondo, and A. Sánchez Palacín, "Tendencias actuales en el uso de dispositivos móviles en educación," La Educ. Digit. Mag., vol. 147, p. 21, 2012.

[3] OECD, "Schooling for Tomorrow Personalising Education," 2006. [Online]. Available: http://www.oecd.org/education/school/36234148.pdf [Accessed: Jun. 04, 2020]

[4] A. Villa and M. Poblete, "Aprendizaje basado en competencias: una propuesta para la evaluación de las competencias genéricas”. Bilbao España: Mensajero, 2007. https://doi. org/10.20868/upm.thesis.48852

[5] UNESCO, "Personalized Learning," 2017. [Online]. Available: https://unesdoc.unesco. org/ark:/48223/pf0000250057 [Accessed: Jun. 04, 2020]

[6] Universidad del Valle de México, "La importancia de la retroalimentación en los procesos de evaluación," Querétaro, 2009.

[7] A. Acosta Gonzaga, E., Rodríguez Mancera, J. A., and Ferrer Soto, "Objetos de Aprendizaje para Dispositivos Móviles Como Herramientas Generadoras de Ventajas en el Proceso de Aprendizaje," UPIICSA, vol. 18, 2010.

[8] B. Rosanigo, P. Bramati, A. Paur, M. Saenz Lopez, G. Bianchi, and E. Livigni, "Repositorio de Objetos de Aprendizaje," SEDECI, 2009. 
[9] M. Kalogiannakis, S. Papadakis, "Combining mobile technologies in environmental education: A Greek case study”, International Journal of Mobile Learning and Organisation, vol. 11, no. 2, pp. 108-130, 2017.

[10] S. Papadakis, M. Kalogiannakis, N. Zaranis, "The effectiveness of computer and tablet assisted intervention in early childhood students' understanding of numbers. An empirical study conducted in Greece", Education and Information Technologies, vol. 23, no. 5, pp. 1849-1871, 2018

[11] P. Dorouka, S. Papadakis, M. Kalogiannakis, "Tablets and apps for promoting robotics, mathematics, STEM education and literacy in early childhood education", International Journal of Mobile Learning and Organisation, vol. 14, no. 2, pp. 255-274, 2020.

[12] S. Papadakis, J. Vaiopoulou, M. Kalogiannakis, D. Stamovlasis, "Developing and Exploring an Evaluation Tool for Educational Apps (ETEA) Targeting Kindergarten Children", Sustainability, vol. 12, no. 10, pp. 4201, 2020. https://doi.org/10.3390/su12104201

[13] K. Meenakshi, R. Sunder, A. Kumar, and N. Sharma, "An intelligent smart tutor system based on emotion analysis and recommendation engine," in 2017 International Conference on IoT and Application (ICIOT), 2017, pp. 1-4. https://doi.org/10.1109/iciota.2017.80736 08

[14] M. Abech, C. A. da Costa, J. L. V. Barbosa, S. J. Rigo, and R. da Rosa Righi, "A model for learning objects adaptation in light of mobile and context-aware computing," Pers. Ubiquitous Comput., vol. 20, no. 2, pp. 167-184, Apr. 2016. https://doi.org/10.1007/s00 779-016-0902-3

[15] H. Imran, M. Belghis-Zadeh, T.-W. Chang, Kinshuk, and S. Graf, "PLORS: a personalized learning object recommender system," Vietnam J. Comput. Sci., vol. 3, no. 1, pp. 3-13, Feb. 2016. https://doi.org/10.1007/s40595-015-0049-6

[16] L. Bhatia and S. S. Prasad, "COPAL - Cognitive personalized aid for learning," in 2015 International Conference on Cognitive Computing and Information Processing (CCIP), 2015, pp. 1-6. https://doi.org/10.1109/ccip.2015.7100698

[17] C. B. Yao, "Constructing a User-Friendly and Smart Ubiquitous Personalized Learning Environment by Using a Context-Aware Mechanism," IEEE Trans. Learn. Technol., vol. 10, no. 1, pp. 104-114, Jan. 2017. https://doi.org/10.1109/tlt.2015.2487977

[18] R. A. W. Tortorella and S. Graf, "Considering learning styles and context-awareness for mobile adaptive learning," Educ. Inf. Technol., vol. 22, no. 1, pp. 297-315, Jan. 2017. https://doi.org/10.1007/s10639-015-9445-x

[19] S. Benhamdi, A. Babouri, and R. Chiky, "Personalized recommender system for eLearning environment,” Educ. Inf. Technol., vol. 22, no. 4, pp. 1455-1477, Jul. 2017. https ://doi.org/10.1007/s10639-016-9504-y

[20] S. S. Oyelere, J. Suhonen, G. M. Wajiga, and E. Sutinen, "Design, development, and evaluation of a mobile learning application for computing education," Educ. Inf. Technol., vol. 23, no. 1, pp. 467-495, Jan. 2018. https://doi.org/10.1007/s10639-017-9613-2

[21] A. El Mhouti, A. Nasseh, M. Erradi, and J. M. Vasquez, "Using cloud computing and a multi-agents system to improve collaborative e-learning in LMS," in 2016 11th International Conference on Intelligent Systems: Theories and Applications (SITA), 2016, pp. 16. https://doi.org/10.1109/sita.2016.7772304

[22] M. Manso Vazquez and M. Llamas Nistal, "A Monitoring System to Ease Self-Regulated Learning Processes,” IEEE Rev. Iberoam. Tecnol. del Aprendiz., vol. 10, no. 2, pp. 52-59, May 2015. https://doi.org/10.1109/rita.2015.2417952

[23] D. Al-Jumeily, A. Hussain, M. Alghamdi, D. Lamb, and H. Hamdan, "The development of an intelligent tutorial system for system development," in 2014 International Conference 
on Web and Open Access to Learning (ICWOAL), 2014, pp. 1-6. https://doi.org/10.1109/ icwoal.2014.7009202

[24] J. Wang, H.-F. Ho, and Y. Ono, "Enhancing Personalized Feedback System by Visual Biometric Data Analysis," in 2016 5th IIAI International Congress on Advanced Applied Informatics (IIAI-AAI), 2016, pp. 410-413. https://doi.org/10.1109/iiai-aai.2016.231

[25] G. G. Castro, E. L. Dominguez, Y. H. Velazquez, M. R. Matla, C. E. Toledo, S. P. Hernandez, "MobiLearn: context-aware mobile learning system", IEEE Latin America Transactions, vol. 14, no. 2, pp. 958-964, 2016. https://doi.org/10.1109/tla.2016.7437246

[26] A. Sharma, "A proposed e-learning system facilitating recommendation using content tagging and student learning styles," in 2017 5th National Conference on E-Learning \& ELearning Technologies (ELELTECH), 2017, pp. 1-6. https://doi.org/10.1109/eleltech.20 17.8074989

[27] M. Milutinović, A. Labus, V. Stojiljković, Z. Bogdanović, and M. Despotović-Zrakić, "Designing a mobile language learning system based on lightweight learning objects," Multimed. Tools Appl., vol. 74, no. 3, pp. 903-935, Feb. 2015. https://doi.org/10.1007/s $\underline{11042-013-1704-5}$

[28] A. Catalina, G. Domingo, and Honey Peter, Los estilos de aprendizaje Procedimientos de diagnóstico y mejora (Septima ed.), Mensajero. Bilbao, 2012.

[29] ISO, "ISO/IEC 25010:2011(en), Systems and software engineering — Systems and software Quality Requirements and Evaluation (SQuaRE) - System and software quality models.” [Online]. Available: https://www.iso.org/obp/ui/\#iso:std:iso-iec:25010:ed-1:v1:e n. [Accessed: 25-Aug-2019]. https://doi.org/10.5220/0005097303630368

[30] Human-Computer Interation Lab University of Maryland, "QUIS: The Questionnaire for User Interaction Satisfaction,” [Online]. Available: http://www.cs.umd.edu/hcil/quis/. [Accessed: Jun. 04, 2020]

[31] D. Rosenberg, M. Stephens, Introduction to ICONIX Process. In: Use Case Driven Object Modeling with UML, 2007, pp. 1-29, https://doi.org/10.1007/978-1-4302-0369-8_1

[32] A. Osmani, Learning JavaScript Design Patterns, USA: O’Reilly Media, 2012, pp. 111138.

[33] P. Software, “Spring Framework," 2019. [Online]. Available: https://spring.io/. [Accessed: Jun. 04, 2020]

[34] Google, "Guide to app architecture," 2019. [Online]. Available: https://developer.android. com/jetpack/docs/guide. [Accessed: Jun. 04, 2020]

[35] J. Nielsen, "How Many Test Users in a Usability Study?", NN/g Nielsen Norman Group, 2012, Available: https://www.nngroup.com/articles/how-many-test-users/ [Accessed: 23March-2020]

[36] G. Vavoula, M. Sharples, "Meeting the challenges in evaluating mobile learning: a 3-level evaluation framework", Int. J. Mobile Blended Learn, vol. 1, no. 2, pp. 54-75, 2009. https://doi.org/10.4018/jmbl.2009040104

\section{Authors}

César Huerta Guerrero is a student of the master's program in applied computing at the National Laboratory on Advanced Informatics (LANIA), in the 2017-2019 generation. Currently, his research interests are focused on software engineering and software development.

Eduardo López Domínguez is a researcher in the Department of Computer Science at Laboratorio Nacional de Informática Avanzada (LANIA), in Veracruz, Mexi- 
co. He completed his PhD Degree at the National Institute of Astrophysics, Optics and Electronics (INAOE), Mexico in 2010. Since 2004, he has been researching in the field of mobile distributed systems, partial order algorithms and multimedia synchronization.

Yesenia Hernández Velázquez is a researcher in the Department of Computer Science at Laboratorio Nacional de Informática Avanzada (LANIA), in Veracruz, Mexico. She completed her MSc Degree at the Benemérita Universidad Autónoma de Puebla (BUAP), Mexico in 2011. Since 2009, she has been researching in the field of mobile learning systems.

Saúl Domínguez Isidro is a researcher in the Department of Computer Science at Laboratorio Nacional de Informática Avanza-da (LANIA), in Veracruz, Mexico. He completed his Ph.D. Degree on the Artificial Intelligence program at the University of Veracruz, Mexico in 2017. Since 2010, he has been researching in the field of softcomputing.

Jorge De La Calleja is an associate professor of computer science at Universidad Politécnica de Puebla (UPPuebla). He received his $\mathrm{PhD}$ in Computer Science in March 2008 from the National Institute of Astrophysics, Optics and Electronics (INAOE), Mexico. His research interests include machine learning and computer vision.

María Auxilio Medina Nieto is an associate professor of computer science at Universidad Politécnica de Puebla (UPPuebla). Currently, her research topics are knowledge representation based on ontologies, semantic web, information and communications technologies (TICs) and social network analysis. She has the candidate status of the National Researchers System (SNI).

Arturo Cueto García is a student of the master's program in applied computing at the National Laboratory on Advanced Informatics (LANIA), in the 2017-2019 generation. Currently, his research interests are focused on software engineering and software development.

Article submitted 2020-06-22. Resubmitted 2020-09-05. Final acceptance 2020-09-06. Final version published as submitted by the authors 